\title{
A Cross-Sectional Study on Sugar-Sweetened Beverages Consumption Patterns and Nourish Status Among Students at Faculty of Medicine of Sarajevo University
}

\author{
Amra Catovic ${ }^{1, *}$, Mensura Besir ${ }^{2}$ \\ ${ }^{1}$ Faculty of Medicine, University of Sarajevo, Sarajevo, Bosnia and Herzegovina \\ ${ }^{2}$ Health Centre "Dom zdravlja Donji Vakuf", Donji Vakuf, Bosnia and Herzegovina \\ Email address: \\ amra.catovic@mf.unsa.ba (A. Catovic), mensurabe@hotmail.com (M. Besir) \\ ${ }^{*}$ Corresponding author
}

To cite this article:

Amra Catovic, Mensura Besir. A Cross-Sectional Study on Sugar-Sweetened Beverages Consumption Patterns and Nourish Status Among Students at Faculty of Medicine of Sarajevo University. Biomedical Sciences. Vol. 6, No. 3, 2020, pp. 52-55.

doi: $10.11648 /$ j.bs.20200603.12

Received: June 30, 2020; Accepted: July 15, 2020; Published: July 28, 2020

\begin{abstract}
Emerging adulthood is typically defined as 18-25 years of age. It may be a particularly important time for establishing long-term health behavior patterns. The transition between adolescence and adulthood is a period of increased risk for excess weight gain, because of shifts in activity patterns as well as declines in overall-diet quality. Sugar-sweetened beverages, a great source of added sugar to the diet, contribute to energy imbalance. A small, persistent energy imbalance of 50 calories per day could result in a 5-pound weight gain over the course of one year. This study aimed to assess the nourish status in a sample of students from Faculty of Medicine of Sarajevo University and correlate it with student consumption pattern of sugar-sweetened beverages. A cross-sectional survey of 246 students was performed during May 2018, at the Sarajevo University. Verbal informed consent was obtained from all participants before completing the self-administered questionnaire that included questions on their frequency of consumption of SSBs eating habits and anthropometrics measures, weight and height. Body mass index was used to assess students nourish status. Statistical analyses were performed using the Statistical Package for Social Sciences software (IBM, version 23.0). Results were expressed as percentages and means \pm standard deviations. This study showed that the majority of the students $(69.26 \%)$ were of normal weight. One quarter of sample $(26.83 \%)$ had BMI $>24.9$. Intake of soda was more common among students with BMI $\geq 25 \mathrm{~kg} / \mathrm{m}^{2}$ than students with BMI $\leq 24.9 \mathrm{~kg} / \mathrm{m}^{2}$ (78.79\% vs. $63.89 \%$ respectively). Among students with BMI $\leq 24.9 \mathrm{~kg} / \mathrm{m}^{2}, 73.33 \%$ reported drinking energy drink never compared to $42.42 \%$ students with BMI $\geq 25 \mathrm{~kg} / \mathrm{m}^{2}$. This study gives baseline information about weight status and consumption pattern of SSBs among a sample of university students. Regulating the intake of free sugars could be used as an approach for successful body weight control.
\end{abstract}

Keywords: Obesity, Weight Gain, Wishnofsky's Rule, Emerging Adulthood

\section{Introduction}

Abnormal or excessive fat accumulation defined overweight and obesity. A crude anthropometric population measure is the body mass index (BMI), a person's weight (in kilograms) divided by the square of person's height (in meters). Those with a body mass index (BMI) of greater than or equal to 25 are considered being overweight, whilst those with a BMI greater than or equal to 30 are considered being obese [1]. Obesity is associated with major causes of death and disability. Not only in high income countries, overweight and obesity are now dramatically on the rise in low-and middle-income countries, particularly in urban settings [2].

According to intercountry comparable overweight and obesity estimation from $2008,60.7 \%$ of the adult population (> 20 years old) in Bosnia and Herzegovina were overweight and $26.5 \%$ were obese. The prevalence of overweight was higher among men (63.7\%) than women (58.0\%). The proportion of men and women that were obese was $23.8 \%$ and $28.9 \%$, respectively. Adulthood obesity prevalence 
forecasts predict that in $203019 \%$ of men and $20 \%$ of women will be obese [3].

Many causes of obesity are the result of multiple changes that have affected various aspects of contemporary life, including physical activity and food consumption patterns. There is a problem to maintain energy balance when sedentary lives are the norm and high-calorie diets are ubiquitous [2].

In recent years, there have been concerns about sugar-sweetened beverages (SSBs) consumption and its impact on health [4]. SSBs are defined to include all beverages containing added caloric sweeteners, including, but not limited to, sugar-or otherwise calorically sweetened regular sodas, less than 100 percent fruit drinks, energy drinks, sports drinks, and ready-to-drink teas and coffees, sweetened milk or milk alternatives, and any beverage to which sugar has been added (typically high fructose corn syrup or table sugar) $[4,5]$.

A consumption of SSBs under isocaloric conditions seems not to affect body weight, but when they are consumed in addition to the normal diet they provide excess calories. Containing the same amount of energy SSBs compared to solid food are less filling. Because of its calories contribution in the diet it is consider to have impact on the epidemic of obesity $[6,7]$.

Body fat, or adipose tissue, is composed of a mixture of mostly fat, some protein, and water due to Bozenrad's chemical analysis. A pound of body fat $(454 \mathrm{~g})$ is approximately 87 percent fat, or $395 \mathrm{~g}$ fat (454 x 0.87$)$. Based on Bozenrad's samples the caloric equivalent of one pound of body weight lost or gained is approximately $3500 \mathrm{kcal}(395 \mathrm{~g}$ $\mathrm{x} 9.3 \mathrm{kcal} / \mathrm{g})$. It is Wishnofsky's Rule (3500 kcal per pound rule). It means that for each 3500 kcalories eaten in excess, a pound of body weight is gained; similarly, a pound of weight is lost for each 3500 kcalories expended beyond those consumed [8]. Applying Wishnofsky's Rule it can be predicted that a small, persistent energy imbalance of 50 calories per day $(50 \mathrm{kcal}$ x 365 days $=18250 \mathrm{kcal})$ could result in a 5-pound weight gain over the course of one year (18250/3500).

Reference [9] provides information about energy content of some beverages. A conventional 12-ounce serving (a 12 ounce can) of soda has between about 125 and $180 \mathrm{kcal}$. A glass (8 ounces) of fruit juice contains between about 100 and $150 \mathrm{kcal}$. Bottled tea brands can have up to $150 \mathrm{kcal}$ in a 12 -ounce serving. Prepackaged chocolate milk can give 140 to more than $250 \mathrm{kcal}$, depending on whether it's low-fat or whole milk. An 8-ounce serving of an energy drink gives $150 \mathrm{kcal}$. Coffee itself almost does not contain calories, but in combination with other ingredients calorie content is changed. Thus 1 cappuccino portion for $8 \mathrm{oz}$ cup contains $75 \mathrm{kcal}$.

Although beverage consumption impacts health, few nationally studies on dietary intakes of SSBs have been done. SSBs are a major contributor of calories in the US diet. National dietary surveys indicate that $49.3 \%$ of US adults consumed 1 or more SSBs on a given day during 2011-2014 [10]. The studies conducted in EU have variations in design in means of reporting of SSB consumption levels. Nevertheless
Western Europe reported the highest levels of overall consumption. Netherlands and Belgium were the top SSBs consumers [11].

SSBs consumption patterns of general population, as well as of young adults, have been limited explored in Bosnia and Herzegovina. Exploring this health-related factor is necessary to implement a nutrition and health promotion program. This study aimed to assess the nourish status in a sample of students from Faculty of Medicine of Sarajevo University and correlate it with student SSBs consumption pattern.

\section{Methods}

\subsection{Design and Sample}

A cross-sectional study was conducted during May 2018 at Faculty of Medicine of Sarajevo University. The survey covered 246 students from the first to the sixth year of study, both sexes, different age groups. Simple random sampling was used to select respondents from different age groups.

The study was conducted according to the research ethics guidelines laid down in the Declaration of Helsinki [12]. Verbal informed consent was obtained from all students before completing the self-administered questionnaire.

\subsection{Data Collection}

The research instrument was a self-administered questionnaire, which was consisted of two parts. In the first part of the survey questionnaire, questions were related to age, sex, weight, and height. In the second part of the survey questionnaire, students gave data on the frequency of consumption of SSBs. There were seven possible answers according to frequency of consumption: (1) never, (2) once a week, (3) twice to three times per week, (4) four to six times per week, (5) once per day, (6) twice per day, (7) three or more times per day. These seven response categories were later merged into three categories for analysis purposes, namely: (1) never, (2) two to three times per week, and (3) consumption on daily basis-often.

Self-reported height and weight were used to calculate BMI $\left(\mathrm{kg} / \mathrm{m}^{2}\right)$. According to guidelines stated by the World Health Organization [1] weight status was classified into four categories: under-weight (BMI $\leq 18.5$ ), normal weight (BMI between 18.5-24.9), overweight (BMI between 25-29.9), and obese (BMI $\geq 30$ ).

\subsection{Data Analysis}

Statistical analyses were performed using the Statistical Package for Social Sciences software (IBM, version 23.0). Results were expressed as percentages and means \pm standard deviations. All of the analyzed variables were non-parametric, so Chi-Square test was used to find whether there is any statistically significant difference between obesity and SSBs consumption pattern. Differences were considered statistically significant at $\mathrm{p}<0.05$. 


\section{Results}

\subsection{General Information of Students Participated in the Study}

A sample included 246 students, of which 164 (66.67\%) were female and $82(33.33 \%)$ were male.

The mean age of students participated in the study was $23.12 \pm 0.19$ year.

The mean weight was $70.40 \pm 0.930 \mathrm{~kg}$ and the mean height was $173.97 \pm 0.590 \mathrm{~cm}$.

The mean BMI was $23.08 \pm 0.21 \mathrm{~kg} / \mathrm{m}^{2}$ (Table 1).

Table 1. General information of students participated in the study.

\begin{tabular}{ll}
\hline Variable & Total \\
\hline Number of students $(\%)$ & $246(100.00 \%)$ \\
Number of females $(\%)$ & $164(66.67 \%)$ \\
Number of males $(\%)$ & $82(33.33 \%)$ \\
Age (mean \pm SD) & $23.12 \pm 0.19$ year \\
Weight (mean \pm SD) & $70.40 \pm 0.93 \mathrm{~kg}$ \\
Height (mean \pm SD) & $173.97 \pm 0.59 \mathrm{~cm}$ \\
BMI (mean $\pm S D)$ & $23.08 \pm 0.21 \mathrm{~kg} / \mathrm{m}^{2}$ \\
\hline
\end{tabular}

\subsection{Students' Nourish Status Based on BMI Categories}

It is showed by Table 2 that the majority of the students $(66.26 \%)$ were of normal weight.

One quarter of sample $(26.83 \%)$ had BMI $>24.9$, whereas $17(6.91 \%)$ students were underweight.
Table 2. General information of students participated in the study.

\begin{tabular}{ll}
\hline BMI & Number (\%) \\
\hline Underweight* & $17(6.91)$ \\
Normal $^{* *}$ & $163(66.26)$ \\
Overweight*** $_{\text {Obese**** }}^{* * 25.20)}$ \\
\hline
\end{tabular}

*Underweight $\left(\mathrm{BMI} \leq 18.5 \mathrm{~kg} / \mathrm{m}^{2}\right)$,

** Normal (BMI between 18.5-24.9 kg/m²),

*** Overweight (BMI between 25-29.9 kg/ $\mathrm{m}^{2}$ ),

$* * * *$ Obese (BMI $\geq 30 \mathrm{~kg} / \mathrm{m}^{2}$ ).

\subsection{Students' SSBs Consumption Habits}

Frequency of SSBs consumption was correlated with nourish status (Table 3).

There were differences in consumption frequency of soda (chi-squared test: $\mathrm{P}=0.019$ ) and energy drink (chi-squared test: $\mathrm{P}<0.0005$ ).

Intake of soda was more common among students with BMI $\geq 25 \mathrm{~kg} / \mathrm{m}^{2}$ than students with BMI $\leq 24.9 \mathrm{~kg} / \mathrm{m}^{2}$ (78.79\% vs. $63.89 \%$ respectively). Among students with BMI $\leq 24.9 \mathrm{~kg} / \mathrm{m} 2,73.33 \%$ reported drinking energy drink never compared to $42.42 \%$ students with BMI $\geq 25 \mathrm{~kg} / \mathrm{m}^{2}$. Consumption frequency of other SSB had no differences regarding to nourish status.

Table 3. Correlation between frequency of SSBs consumption and nourish status.

\begin{tabular}{|c|c|c|c|c|c|c|}
\hline \multirow{2}{*}{ SSBs } & \multirow{2}{*}{ Frequency of consumption } & \multicolumn{2}{|c|}{$\mathrm{BMI} \leq 24.5(\mathrm{~N}=180)$} & \multicolumn{2}{|c|}{$\mathrm{BMI} \geq 25(\mathrm{~N}=66)$} & \multirow{2}{*}{$\mathbf{P}$} \\
\hline & & $\mathbf{N}$ & $\%$ & $\mathbf{N}$ & $\%$ & \\
\hline \multirow{3}{*}{ Flovored water } & never & 112 & 62.22 & 39 & 59.09 & \multirow{3}{*}{0.789} \\
\hline & weekly & 56 & 31.11 & 21 & 31.82 & \\
\hline & daily & 12 & 6.67 & 6 & 9.09 & \\
\hline \multirow{3}{*}{ Tea } & never & 83 & 46.11 & 28 & 42.42 & \multirow{3}{*}{0.534} \\
\hline & weekly & 72 & 40.00 & 25 & 37.88 & \\
\hline & daily & 25 & 13.89 & 13 & 19.70 & \\
\hline \multirow[t]{2}{*}{ Cofee } & weekly & 37 & 20.56 & 11 & 16.67 & \multirow[t]{2}{*}{0.790} \\
\hline & daily & 97 & 53.89 & 37 & 56.06 & \\
\hline \multirow{3}{*}{ Chocolate milk } & never & 91 & 50.56 & 36 & 54.55 & \multirow{3}{*}{0.117} \\
\hline & weekly & 60 & 33.33 & 26 & 39.39 & \\
\hline & daily & 29 & 16.11 & 4 & 6.06 & \\
\hline \multirow[b]{2}{*}{ Fruit juice } & never & 34 & 18.89 & 11 & 16.67 & \multirow[b]{2}{*}{0.458} \\
\hline & weekly & 117 & 65.00 & 48 & 72.72 & \\
\hline \multirow{3}{*}{ Vitamin drink } & never & 92 & 51.11 & 26 & 39.39 & \multirow{3}{*}{0.262} \\
\hline & weekly & 65 & 36.11 & 30 & 45.46 & \\
\hline & daily & 23 & 12.78 & 10 & 15.15 & \\
\hline \multirow{3}{*}{ Soda } & never & 65 & 36.11 & 14 & 21.21 & \multirow{3}{*}{0.019} \\
\hline & weekly & 92 & 51.11 & 47 & 71.21 & \\
\hline & daily & 23 & 12.78 & 5 & 7.58 & \\
\hline \multirow{3}{*}{ Energy drink } & never & 132 & 73.33 & 28 & 42.42 & \multirow{3}{*}{$<0.0005$} \\
\hline & weekly & 41 & 22.78 & 31 & 46.97 & \\
\hline & daily & 7 & 3.89 & 7 & 10.61 & \\
\hline
\end{tabular}

\section{Discussion}

The age group known as emerging adults, generally ages 18 to 25 , is at risk for developing obesity and obesity-related conditions. Body weight continuously rises until graduation
[13]. The transition into new lifestyle is associated with disturbance in a diet, and insufficient physical activity. To establish effective intervention strategies it is important to explore factors that may contribute to this rise in obesity.

The purpose of this study was to assess the nourish status in a sample of students from Faculty of Medicine of Sarajevo 
University and correlate it with student SSBs consumption pattern. A sample included 246 students, of which 164 $(66.67 \%)$ were female and $82(33.33 \%)$ were male. The mean age of students participated in the study was $23.12 \pm 0.19$ year. The mean BMI was $23.08 \pm 0.21 \mathrm{~kg} / \mathrm{m}^{2}$. A quarter of sample $(26.83 \%)$ had BMI $>24.9$.

Correlation between frequency of SSBs consumption and nourished status reveled differences in consumption frequency of soda and energy drink. Intake of soda was more common among students with BMI $\geq 25 \mathrm{~kg} / \mathrm{m}^{2}$ than students with BMI $\leq 24.9 \mathrm{~kg} / \mathrm{m}^{2}$ (78.79\% vs. $63.89 \%$ respectively). Among students with BMI $\leq 24.9 \mathrm{~kg} / \mathrm{m}^{2}, 73.33 \%$ reported drinking energy drink never compared to $42.42 \%$ students with $\mathrm{BMI} \geq 25 \mathrm{~kg} / \mathrm{m}^{2}$.

The role of SSBs in increasing obesity was evaluated in numerous studies with opposite results [15]. Nevertheless SSBs are a leading source of added sugar to the diet in some group. It is general trend that young adults and adolescents tend to consume more SSBs than older adults [10, 11]. Some environmental interventions that reduce availability of SSBs course decline in SSBs consumption rates, but added sugars are still beyond the recommendation (less than $10 \%$ of calories per day) [5].

As college students experience weight gain they should be aware of impact of SSBs. If they plan weight loss/control calculation of energy content of SSBs is necessary. Health education programming may benefit from the use of health/fitness apps, so called mHealth.

\section{Conclusion}

The present study gives baseline information about corralation between weight status and SSBs conumption among a sample of university students. Sugar sweetened beverages may lead to weight gain through the high added sugar content, low satiety, and increased energy intake. Educating students to limit SSBs intake could improve their health. Specific health education programs, based on mHealth could motivate students and to improve their health.

\section{Conflict of Interests}

The authors declare that they have no competing interests.

\section{References}

[1] World Health Organization (2000). Obesity. Preventing and managing the global epidemic. Report on a WHO consultation on Obesity. Technical Report Series Number 894. Geneva. World Health Organization. www.who.int > WHO_TRS_894.

[2] Institute of Medicine. (2012). Accelerating progress in obesity prevention: solving the weight of the nation. Washington, DC: The National Academies Press. https://doi.org/10.17226/13275.

[3] World Health Organization/Regional Office for Europe. (2013). Diet, Physical Activity and Obesity, Bosnia and Herzegovina. http://www.euro.who.int/en/nutrition-country-profiles.

[4] Prinz, P. (2019). The role of dietary sugars in health: molecular composition or just calories? European Journal of Clinical Nutrition, 73: 1216-1223.

[5] Welsh, J. A., Lundeen, E. A., Stein, A. D. (2013). The sugar-sweetened beverage wars: public health and the role of the beverage industry, Curr Opin Endocrinol Diabetes Obes, 20 (5): 401-406.

[6] Centers for Disease Control and Prevention (2010). The CDC Guide to Strategies for Reducing the Consumption of Sugar-Sweetened Beverages, 1-41.

[7] World Health Organization. (2015). Guideline: Sugars intake for adults and children. Geneva: World Health Organization. https://www.who.int/publications/i/item/9789241549028.

[8] Hall, K. D., Sacks, G., Chandramohan, D., Chow, C. C., Wang, Y. C., Gortmaker, S. L., Swinburn, B. A. (2011). Quantification of the effect of energy imbalance on body weight. Lancet, 378: 826-837.

[9] WebMD. Diet \& Weight Management. Slideshows. Drinks with as many calories as soda. https://www.webmd.com/diet/ss/slideshow-drinks-same-calori es-soda.

[10] Rosinger, A., Herrick, K., Gahche, J., Park, S. (2017). Sugar-sweetened beverage consumption among US adults, 2011-2014. NCHS Data Brief, 270: 1-8.

[11] European Commission (2018). Fruit juices, sugar sweetened beverages and artificially sweetened beverages: consumption patterns and impact on overweight and obesity. Review of Scientific Evidence and Policies on Nutrition and Physical Activity-Objective B2: Consumption, energy intake and impact of fruit juices and of artificially and sugar sweetened beverages. Luxembourg: Publications Office of the European Union.

[12] World Medical Association Declaration of Helsinki (2008). Ethical Principles for Medical Research Involving Human Subjects.

[13] Gropper, S. S., Simmons, K. P., Connell, L. J., Ulrich, P. V. (2012). Changes in body weight, composition, and shape: a 4-year study of college students. App Phys Nut Met 37: 1118-1123.

[14] Nelson, M. C., Story, M., Larson, N. I., Neumark-Sztainer, D., Lytle, L. A. (2008). Emerging adulthood and college-aged youth: an overlooked age for weight-related behavior change. Obesity (Silver Spring). 16 (10): 2205-2211.

[15] Bleich, S. N., Vercammen, K. A., Koma, J. W., Li, Z. (2017). Trends in Beverage Consumption Among Children and Adults, 2003-2014. Obesity 26 (2). 